\title{
Young Football Players Are Not Miniature Adults; Do Young Athletes Need Sports Drinks? : A Review of Literature
}

\author{
Siti Azilah $\operatorname{Atan}^{1^{*}}$ and Mohar Kassim ${ }^{1}$ \\ ${ }^{1}$ Defence Fitness Academy, National Defence University of Malaysia, \\ Kem Sungai Besi, 57000, Kuala Lumpur, Malaysia
}

\begin{abstract}
This review aims to highlight the differences in physiological demands between youth versus adult male football players during prolonged intermittent exercise such as substrate utilisation, limited glycogen stores, lower aerobic and anaerobic capacity as well as control of body temperature. Furthermore, we also aim to provide an overview and summarise the limited data available in carbohydrate-electrolytes (CHO-E) supplementation in young football players. During exercise, sweating is the optimal way to maintain body temperature. In order to prevent from dehydrating, water intake is crucial to avoid a deterioration of performance, especially towards the end of football matches. Water is the most common fluid replacer in many young athletes' sports events; however, sports drinks intake has grown exponentially among this population. Many studies in adults had used a football simulation protocol such as the Loughborough Intermittent Shuttlerunning Test and showed positive effects of sports drinks including delaying fatigue, maintaining sprint and skill performance as well as assisting thermoregulatory processes. When seeking the effectiveness of sports drinks/carbohydrate-electrolyte beverages, the information in youth football is still lacking. Young football players are not 'miniature adults' due to variations in physiological/metabolic demands during prolonged intermittent activities in football. In addition, the playing time is less than adults ( $<90 \mathrm{~min}$ ), which may not be a sufficient duration for sports drinks to be effective. Therefore, it can be concluded that young football players may prioritise fluid replacement more than carbohydrate replacement as water might be better than sports drinks.
\end{abstract}

Keywords: adolescents; carbohydrate; football; hydration; intermittent exercise

\section{INTRODUCTION}

There is a growing body of literature that recognises the importance of nutritional ergogenic aids in adult football players where the aims are to enhance football performance and gain competitive advantages over competitors (Gant, Ali, \& Foskett, 2010; Russell \& Kingsley, 2014). One of the most popular nutritional strategies that has been shown to be effective with scientific evidences such as maintaining football skill performance (Ali et al., 2007) and endurance capacity during intermittent high-intensity running (Nicholas, Williams, Lakomy, Phillips, \& Nowitz, 1995) is sports drinks (Ali et al., 2007; Patterson \& Gray, 2007; Currell, Conway \& Jeukendrup, 2009; Russell, Benton \& Kingsley, 2011). Sports drinks typically contain electrolytes (mainly sodium and potassium) with added sugar (various combinations of sucrose, glucose, fructose and maltodextrin); however, the amount and flavour are dependent on the manufacturer (Smith, 1992). The presence of carbohydrate-electrolytes (CHO-E) in sports drinks may aid to support metabolism and optimise hydration status, particularly during prolonged vigorous physical activity or in hot temperatures (Maughan, 1998; Sawka \& Montain, 2000). Furthermore, acceptable palatability is also encouraging consumption (Maughan, 
1998). Consequently, the inclusion of sports drinks during training and competition is common in many athletes, young football players included (Care, 2011; Larson et al., 2014).

With 22 million youth football players around the globe (Kunz, 2007), the efficacy of CHO-E ingestion in youth football is limited compared to their adult counterparts (Phillips et al., 2010, 2012). Indeed, most of the recommendations given for young athletes are based on findings from studies using adult players (Montfort-Steiger \& Williams, 2007). It is important to note that during the transition period from childhood to puberty, there are several developmental milestones such as changes in body size and composition, the development of cardiorespiratory with primary and secondary sex characteristics. Therefore, towards maturation, various physiological differences are observed and expected in young football players (relative to adults) (Naughton et al., 2000). Considering the physiological discrepancies such as substrate utilisation, reduced reserves of muscle glycogen, lower aerobic and anaerobic capacity, and less well-developed thermoregulatory processes (Timmons, Bar-Or \& Riddell, 2003; Alvarado, 2005; Rosenbloom, Loucks \& Ekblom, 2006; Riddell, 2008) during prolonged intermittent exercise, young players may respond differently to $\mathrm{CHO}-\mathrm{E}$ supplementation.

Moreover, previous researches have proposed the importance of hydration or fluid replacement in football at any climate, but can be more detrimental in hot and high humidity areas (Casa et al., 2000; Monteiro, Guerra \& Barros, 2003; Maughan, King \& Lea, 2004). Evidence showed that weight loss of greater than $2 \%$ resulting from dehydration could cause loss of concentration, fatigue, increase heart rate and for a more severe case, circulatory collapse (Smith, 1992). Given that children adapt less well to exercise in the heat and other physiological disadvantages, sports drinks may aid in the supply of substrate, prevention of dehydration, electrolyte replacement, pre-hydration and post rehydration.

Limited scientific understanding of the benefits of sports drinks consumption within adolescents has also attracted criticism; for instance, frequent or excessive intake may substantially increase the risk of dental erosion (Hooper et al., 2004) and excess weight gain (Larson et al., 2014). Over the past few years, the American Academy of Paediatrics aimed to create awareness and eliminate inappropriate use of sports drinks in young populations
(Care, 2011). This is especially relevant given the sports beverage industry intentionally grabbing teenagers' attention through effective marketing campaigns regarding the optimisation of sports performance (Eating, Story \& Klein, 2012). For instance, in 2010, Gatorade released an advertising campaign based on the slogan 'the sports drinks for the young athlete' which was ranked in the top five most viewed advertisements seen by adolescents with more than 3 million Facebook fans and nearly 30,000 Twitter followers (Harris, Schwartz \& Brownell, 2011). This has helped to promote voluntary sports drinks intake within and outside of - the sport's settings as adolescents believe that sports drinks are a 'healthy' alternative to soda (Eating, Story \& Klein, 2012) along with the idea of performance improvements (Maughan, 1998).

For that reason, further investigations are required to fully understand whether young football players may or may not experience similar performance benefits as adult players. The purpose of this review is to: a) highlight the differences in physiological/metabolic demands on adolescents versus adult male players during prolonged intermittent exercise, and b) provide an overview and summarise the limited data available in CHO-E supplementation in young football players.

\section{MATURATION STATUS}

Compared to adults, young players possess unique characteristics associated with pubertal development. The most noticeable difference is the widespread of biological age and variation in development stages (Malina, Eisenmann, Cumming, Ribeiro, \& Aroso, 2004; Meylan, Cronin, Oliver, \& Hughes, 2010). According to Marshall and Tanner (1970), there are five stages of puberty from childhood to full maturity ( $\mathrm{P}_{1}$ to $\mathrm{P}_{5}$ ), which are based on external primary and secondary sex characteristics. Stage 1 or P1 corresponds with pre-pubertal growth and development, while $\mathrm{P}_{2}$ to $\mathrm{P}_{5}$ indicate the development of pubic hair, testicular volume for boys and breast development for girls (Naughton et al., 2000). Meanwhile, in $\mathrm{P}_{5}$, maturation is completed to the adult type in pubic hair quantity, adult-sized and shaped genitalia for boys and menarche (first menstruation) occurs for girls (Carling, Le Gall, \& Malina, 2012; Naughton et al., 2000).

Progression through puberty includes changes in body size 
and composition, functional capacities as well as physiological changes. Several studies have been carried out to investigate functional capacities to biological maturation (Carling et al., 2009; Malina et al., 2004; Philippaerts et al., 2006; Strøyer, Hansen, \& Klausen, 2004). In Malina et al. (2004), 69 players from the first Portuguese national division (13 to 15 years old) were categorised based on Tanner distribution of stages of pubic hair ( $\mathrm{PH} 1$ to $\mathrm{PH}_{5}$ ). The findings showed that players' in $\mathrm{PH}_{5}$ performance in 3om sprint, vertical jump and yo-yo intermittent endurance running test were significantly greater than players in $\mathrm{PH} 1$ to $\mathrm{PH} 4$. This was further supported by Strøyer et al. ( 2004) who found that players at the end of puberty (EeP) $\dot{\mathcal{V}} O_{2 \max }$ had greater values $\left(63.7 \pm 8.5 \mathrm{~mL}\right.$ 02. $\left.\mathrm{min}^{-1} . \mathrm{kg}^{-1}\right)$ than elite players at the beginning of puberty (EbP) and non-elite players at the beginning of puberty ( $\mathrm{NbP})$. In contrast to earlier findings, no significant differences were noted in body composition (proportion of fat and fat-free mass), vertical jump, 10m and 40m sprint and endurance capacity when 160 elite youth football players in National Institute of Football of France were investigated (Carling et al., 2009). Therefore, it is essential to note that the advantages in greater physique and physical performances should not be used as a single indicator in identifying good youth players (Gil, Ruiz, Irazusta, Gil, \& Irazusta, 2007; Meylan et al., 2010). This is perhaps especially important as body size, and physical capacities will progressively improve as they are getting matured as well as due to training effects (Naughton et al., 2000). Even though there are several methods to assess maturities such as hand-wrist radiograph (Figueiredo et al., 2009) Tanner scales (Marshall \& Tanner, 1970) and peak height velocity (PHV) (Philippaerts et al., 2006), young football players are usually grouped based on their chronological ages (Le Gall, Carling, Williams, \& Reilly, 2010; Meylan et al., 2010). The selection criterion was governed by the Fédération Internationale de Football Association (FIFA) to ensure that adolescents players have equal opportunity and fair competition (Helsen, Van Winckel, \& Williams, 2005).

On the other hand, with the early investigations establishing physical development during the maturity process, the most important underlining that explains the changes during maturity is the hormonal changes (Alvarado,
2005). During the pubertal growth spurt, the development relies on the release of important hormones like insulin-like growth factor (IGFs), growth hormone (GH), sex steroids hormones (SSHs) and catecholamines (Boisseau \& Delamarche, 2000). These hormones are strongly associated with energy metabolism during exercise (Riddell, 2008). This will be discussed in more details in the next section.

\section{SUBSTRATE UTILISATION DURING PROLONGED EXERCISE}

For normal active adults, the contribution of substrates to total energy expenditure is dependent on the range of intensities of exercise; low-intensity exercise $(25 \%$ of $\dot{\mathcal{V}} \mathrm{O}_{2 \text { max }}$ is derived from plasma fatty acids, moderate intensities of exercise $\left(65 \%\right.$ of $\left.\dot{\mathcal{v}} O_{2 \max }\right)$ utilise energy from fat oxidation, while $85 \%$ of $\dot{\mathcal{V}} \mathrm{O}_{2 \text { max }}$ from $\mathrm{CHO}$ oxidation (Coyle, 1995). Contrarily, due to progress towards puberty, substrate utilisations in both aerobic and anaerobic metabolism for young athletes are strongly associated with important hormones like insulin-like growth factor, growth hormone, sex steroid hormones and catecholamines (Boisseau \& Delamarche, 2000).

At this point, there is limited information regarding energy metabolism in adolescents due to methodological and ethical considerations; however, the few studies that have been conducted supported the notion that adolescents have a greater reliance on fat oxidation compared to adults (Boisseau \& Delamarche, 2000; Rosenbloom, Loucks \& Ekblom, 2006; Kostyak et al., 2007; Riddell, 2008). In a longitudinal study of over 3.5 years, Riddell et al. (2008) compared the fat oxidation rate between boys (11 to 12 years) and men (20 to 26 years) over a range of exercise intensities. The findings showed that fat oxidation rate was higher in boys $\left(8.6 \mathrm{mg} \cdot \mathrm{kg}\right.$ lean body $\left.\operatorname{mass}^{-1} \cdot \mathrm{min}^{-1}\right)$ compared to men (4.2mg $\left.\cdot \mathrm{kg}^{-1} \cdot \mathrm{min}^{-1}\right)$. This was further supported by Kostyak et al. (2007), who reported that grams of fat oxidised relative to caloric expenditure were higher in boys $\left(0.047 \mathrm{~g} \cdot \mathrm{kJ}^{-1}\right.$ ) compared to men (0.032g. $\left.\mathrm{kJ}^{-1}\right)$. Interestingly, Timmons et al. (2003) reported that fat oxidation remained considerably high ( $\sim 88 \%)$ in boys than in men, even during exogenous CHO feeding. A possible explanation for higher fat oxidation rates may be due to the secretion of growth hormone during 
the development process that promotes lipolysis activity and fat oxidation (Alvarado, 2005) as well as insulin resistance (Alvarado, 2005; Kostyak et al., 2007; Riddell, 2008). Insulin is a major anabolic hormone which regulates the metabolism and storage of ingested metabolic fuels (Boisseau \& Delamarche, 2000). During the period of insulin resistance, insulin conserves the $\mathrm{CHO}$, which is mainly used for the energy requirements of growth and development (Alvarado, 2005; Riddell, 2008).

In summary, previous studies have consistently indicated that fat oxidation rate is considerably higher in children and adolescents compared to adults. Nevertheless, it was suggested that reliance on fat decreases with advancing pubertal stages, with the greatest decreases occurring during the final stages of maturation (Timmons, Bar-Or \& Riddell, 2007b; Riddell, 2008). However, studies of substrate utilisation in young athletes are too scarce to be conclusive. Given the small sample size in these studies (512 boys); (Kostyak et al., 2007; Timmons, Bar-Or \& Riddell, 2007a; Riddell, 2008), they may not necessarily be representative of the whole population; more research is warranted to examine differences in substrate utilisation in adolescents as our understanding in this area is far from complete.

\section{GLYCOGEN STORAGE}

Muscle glycogen is the predominant substrate for energy production as it provides a direct source of $\mathrm{CHO}$ for muscle energy metabolism (Bangsbo, Mohr, \& Krustrup, 2006; Powers \& Howley, 2001). Krustup et al. (2006) reported that muscle glycogen decreased by $150-350 \mathrm{mmol} \cdot \mathrm{kg}$ dry weight $^{1}$ during football match-play. Depletion of muscle glycogen during prolonged exercise has been linked to fatigue (i.e. decline in physical work); for instance, total distance covered (Bradley et al., 2010; Vigne et al., 2010), the number of sprints (Vigne et al., 2010), and technical skills (Rampinini et al., 2009) decreased substantially in the second half of matches for adult football players. These findings suggest that football is a glycogen-depleting activity, and the muscle glycogen significantly influences work rate. It has been shown that $\mathrm{CHO}$ supplementation may attenuate the effects of glycogen depletion in adult football players (Nicholas et al., 1999).

Adolescents have 50-60\% lower glycogen stores relative to adults (Alvarado, 2005; Rosenbloom, Loucks \& Ekblom, 2006), which could be due to faster depletion of glycogen stores. However, there is limited data in young athletes regarding glycogen depletion rates during exercise as it is limited by invasive procedures such as muscle biopsy (Timmons, Bar-Or \& Riddell, 2007b). The most detailed investigation about paediatric muscle glycogen was conducted over 35 years ago (Eriksson \& Gollnick, 1973). This muscle biopsy investigation showed that muscle glycogen content decreased from $54 \mathrm{mmol} \cdot \mathrm{kg}$ dry weight ${ }^{-1}$ at rest to $34 \mathrm{mmol} \cdot \mathrm{kg}$ dry weight ${ }^{-1}$ at exhaustion (Eriksson \& Gollnick, 1973); however, no subsequent study has been published to confirm this finding.

Nevertheless, young players have been encouraged to increase $\mathrm{CHO}$ content in their diet to maintain muscle glycogen stores to improve performance (Ruiz et al., 2005). Considering the time available and to avoid an upset stomach before a match, sports drinks may be the quickest way to replenish glycogen stores during prolonged matchplay. So far, there is little evidence that young players receive the same benefit (Phillips et al., 2010; Phillips et al., 2012). Further investigation is required; consequently, the proper nutritional strategy can be developed for young athletes who engage in prolonged exercise.

\section{AEROBIC CAPACITY}

Football can be described as a high-intermittent exercise interspersed with periods of active and passive recovery played over a relatively extended duration (Svensson and Drust, 2005). The highly intermittent nature of football during prolonged matches necessitates the use of various energy pathways to fulfil the energy demands, with a greater contribution from aerobic metabolism (Yoav, Machnai \& Eliakim, 2009). For adult players, there are relatively good correlations between aerobic power and distance covered, competitive ranking and quality of play during adult matchplay (Bangsbo \& Lindquist, 1992; Krustrup et al., 2003). Furthermore, improvements in aerobic performance increase time spent in high-intensity activity, number of sprints, touches of the ball and an improved recovery during 
high-intensity activity (Impellizzeri, Rampinini \& Marcora, 2005). Bradley et al. (2010) also showed that elite adult players who had the highest aerobic capacity spent longer in high-intensity activities in comparison to players with moderate aerobic capacity. However, there is no evidence to support the relationship between aerobic capacity and match performance in young players, even though it was recorded that national players displayed higher $\dot{\mathcal{V}} O_{2 \max }$, values, i.e. $52.6 \mathrm{~mL} \cdot \mathrm{kg}^{-1} \cdot \mathrm{min}^{-1}$ and $52.7 \mathrm{~mL} \cdot \mathrm{kg}^{-1} \cdot \mathrm{min}^{-1}$ compared to the worst league team players at $48.8 \mathrm{~mL} \cdot \mathrm{kg}$ ${ }^{1} \cdot \mathrm{min}^{-1}$ (Teplan et al., 2012).

Adolescents' lower aerobic capacity is limited by physical growth (maturation status) and body size (height and weight) (Stølen et al., 2005). Previous research has shown that $\dot{\mathcal{V}} O_{2 \max }$ values for adult players at various levels of competition and playing position (elite, top amateur, university) were between 50 to $75 \mathrm{~mL} \cdot \mathrm{kg}^{-1} \cdot \mathrm{min}^{-1}$ while young football players' $\dot{\mathcal{V}} O_{2 \max }$ values were lower than $6 \mathrm{omL} \cdot \mathrm{kg}$ ${ }^{1} \cdot \mathrm{min}^{-1}$ (Stølen et al., 2005). In 2004, Chamari et al. (2005) introduced the allometric scaling procedure (expressed in relation to lean body mass) which was recognised as a better method to compare aerobic capacity between young and adult football players. This approach showed that young players do have lower $\dot{\mathcal{V}} O_{2 \max }$ values; 14-year-old players: $179 \mathrm{~mL} \cdot \mathrm{lbm}^{0.72} \cdot \mathrm{min}$ and 24-year-old adults: 188 $\mathrm{mL} \cdot \mathrm{lbm}^{0.72} \cdot \mathrm{min}$ (Chamari et al., 2005). Nonetheless, adolescents have a relatively higher reliance on aerobic metabolism during exercise (Riddell, 2008). The aerobic metabolism is much better developed than anaerobic power; for instance, during a $6 \mathrm{~min}$ run, adolescents rely almost entirely on aerobic metabolism (Reilly, Bangsbo \& Franks, 2000). Moreover, it has been suggested that young players may not need to have an extraordinary capacity within any of the areas of physical performances but must possess a reasonably high level within all areas (Reilly et al., 2000). The aerobic capacity will increase with age and improvements after maturation may be more dependent on training effects (Naughton et al., 2000).

\section{ANAEROBIC CAPACITY}

Anaerobic capacity reflects the maximal anaerobic energy production an individual can obtain in any exercise bout performed to exhaustion (Reilly, Bangsbo \& Franks, 2000). Although the contribution of anaerobic activity in football is small, about $1-11 \%$ of high-intensity game activities per match (Reilly \& Thomas, 1976; Mohr, Krustrup \& Bangsbo, 2003) or approximately 150 to 250 brief intense actions (Osgnach et al., 2010), high intensity activities are often crucial for the match outcome; for instance to win possession of the ball, the scoring of goals or to prevent conceding of goals (Reilly, Bangsbo \& Franks, 2000).

During adolescence, anaerobic capacity seems to be less developed than adults since anaerobic power in young players is $50 \%$ than that of their adult counterparts (Nikolaidis, 2011). The major contributing factor to this is players' immature anaerobic metabolic ability during adolescence (Alvarado, 2005). This results in the inferior anaerobic capacity to supply adenosine triphosphate (ATP) during high-intensity exercise. In addition, phosphofructokinase (PFK) activity is lower, therefore reducing the enzyme activity in the glycolytic pathway (Riddell, 2008). Other influences include lower maturation in muscle fibre distribution and immature anabolic hormonal response; for instance, a lower level of testosterone (Naughton et al., 2000). Furthermore, lower blood lactate concentration was also found in adolescents, suggesting a higher reliance on aerobic metabolism (fat oxidation) and immature anaerobic metabolism (Riddell, 2008). As a result, we may expect to see lower sprint number, slower speed and lesser distance covered in highintensity activities for young players.

To date, there is a lack of readily comparable data that allows for a clear description of youth football players' anaerobic capacity (Naughton et al., 2000). It is possible to conclude that adolescents may perform lesser distance, number and frequency in high-intensity activities during matches compared to adults. Even so, anaerobic capacity will progressively improve as age increases, primarily by the gains in body size, muscle mass and increased enzymatic activity (Naughton et al., 2000).

\section{THERMOREGULATION}

During prolonged exercise, the temperature in the body's core rises, and heat loss mechanisms aim to prevent 
overheating (Powers \& Howley, 2001). Young football athletes may have disadvantages compared to adults due to inferior control of body temperature, especially in high environmental temperatures (Alvarado, 2005). According to Falk and Dotan (2008), child-adult differences in thermoregulation are due to morphological, metabolic, cardiovascular insufficiency and sweating rates. Relative to body mass, adolescents have a much greater surface area, and this can be problematic as the skin can absorb heat from the external environment and put more stress upon thermoregulation, especially in hot and humid environments (Rowland, 2008). Furthermore, young athletes expend more energy per kilogram to perform work; for instance, at $10 \mathrm{~km} \cdot \mathrm{h}^{-1}$ running velocity, oxygen consumption and heat production were 10 to $15 \%$ higher than adults (Falk \& Dotan, 2008). Meanwhile, cardiovascular insufficiency, including lower cardiac output and blood volume due to greater reliance on nonevaporative heat dissipation, resulting in a competition of blood flow between working muscles and the skin (Sinclair et al., 2007). Consequently, this places more challenges on young players, and they are more vulnerable to heat injury during exercise in a hot environment (Falk \& Dotan, 2008). Moreover, compared to adults, young athletes have $40 \%$ diminished sweating rate capacity and thus a reduced ability to dissipate heat during exercise (Alvarado, 2005). Perspiration was found to be a great cooling agent for adolescents in hot conditions during non-exercise activity; however, when exercise stress was added, this system was unable to work as effectively (Rowland, 2008). Given these disadvantages during prolonged football matches in youth football, particular care must be taken in preparation for adolescents undertaking sporting activities in hot and humid climates. Previous studies in adults have shown that CHO-E drinks and water may assist in thermoregulation processes (Shi \& Gisolfi, 1998) as well as maintaining football performance (Mcgregor et al., 1999; Ali \& Williams, 2009). This warrants further research investigating the effects of fluid and CHO-E ingestion on thermoregulation in young players.

\section{HYDRATION IN FOOTBALL}

Given the differences between adolescents and adults during prolonged exercise, particular care must be taken to ensure safe participation in youth football. Various studies have shown that young football players were hypohydrated before training or competition. For instance, Silva et al. (2011) had investigated 20 professional football players in a hot and humid environment $\left(33.1 \pm 2.4^{\circ} \mathrm{C}, 43.4 \pm 3.2 \%\right.$, respectively) Hydration status was measured using urine specific gravity (USG), and body mass changes were recorded before and after training sessions. It was found that players began the days of training mildly hypohydrated (USG > 1.020), and fluid intake did not match fluid losses.

Dehydration has various deleterious effects on thermoregulation; consequently, young football players are more vulnerable to heat illnesses, especially when exercising in hot and humid conditions (Rowland, 2008). Fluid losses of $2 \%$ of body mass can impair football performance as well as cognitive functions (Monteiro, Guerra \& Barros, 2003). Research in adults has shown that intermittent highintensity shuttle running exercise in the no-fluid condition resulted in $5 \%$ deterioration in football skill performance (Mcgregor et al., 1999). Furthermore, heart rate, perceived exertion, serum aldosterone, osmolality, sodium and cortisol levels were also higher in the no-fluid relative to the fluid trial (Chamari et al., 2005). In agreement with this, the National Athletic Trainers' Association (NATA) claimed that proper hydration during exercise assists in thermoregulation, cardiovascular function, fluid volume status, muscle functioning as well as exercise performance (Casa et al., 2000). Therefore, it is proposed that football players should drink pre-exercise, during half time break and when they have the opportunity during breaks in play.

Water may be considered the best way for rehydration during exercise; however, considering the loss of electrolytes (such as sodium, potassium, calcium, and magnesium) and glycogen stores during football match-play (Maughan, 1998), CHO-E may offer more advantages than ingesting water alone. For adults, soccer simulation protocols (SSP) have been used widely to investigate several aspects of soccer performance. The protocol must simulate specific movement patterns, total distance covered, the duration of 
responses observed in match-play (Ali \& Williams 2007). Consumption of CHO-E beverages has been shown to increase the concentration of blood glucose (Patterson \& Gray, 2007), enhance oxidation of exogenous CHO (Gant, Ali \& Foskett, 2010) and spare muscle glycogen (Monteiro, Guerra \& Barros, 2003). Regardless of the mechanism of action, CHO-E ingestion has been shown to delay fatigue and improve football performance. Since sports drinks are readily available and have greater application compared to plain water due to palatability and potential ergogenic effects (Larson et al., 2014), it is important to answer the question of whether sports drinks will provide performance benefits beyond the effects of water for young athletes. Recognising the limitation when investigating adolescents, the next section will discuss the limited studies on CHO-E supplementation in youth football.

\section{CARBOHYDRATE- ELECTROLYTE SUPPLEMENTATION IN YOUNG FOOTBALL PLAYERS}

Having evidence that CHO-E ingestion in adults has a significant enhancement in intermittent endurance capacity (Nicholas et al., 1995) as well as better maintenance of skill and sprint performance (Ali et al., 2007), improved thermoregulation and reduced risk of heat injury (Shi and Gisolfi, 1998), it is important to investigate its effects on young football players as well. Notwithstanding limited research on CHO-E ingestion for young football players (Phillips et al., 2010; Phillips et al., 2012), more and more people are wondering if young athletes will experience the same advantages of CHO-E ingestion as their adult counterparts.

There is evidence in the literature to suggest that when 9year-old boys consumed ${ }^{13} \mathrm{C}$-enriched $6 \% \mathrm{CHO}-\mathrm{E}$ solution, the oxidation rate was higher $\left(8.8 \pm 0.5 \mathrm{mg} \cdot \mathrm{kg}^{-1} \cdot \mathrm{min}^{-1}\right)$ than 22-year-old adults $\left(6.2 \pm 0.5 \mathrm{mg} \cdot \mathrm{kg}^{-1} \cdot \mathrm{min}^{-1}\right)$; this represented a greater relative proportion of total energy in the children (21.8\%) relative to adults (14.6\%) (Timmons, Bar-Or \& Riddell, 2003). Timmons et al. (2007b) later reported that CHO-E ingestion ( ${ }^{13} \mathrm{C}$-enriched $6 \%$ CHO-E beverage) decreased fat oxidation and increased $\mathrm{CHO}$ oxidation in 20 boys of the same chronological age (12 years). These findings demonstrate that adolescents have a greater reliance on exogenous $\mathrm{CHO}$ during exercise. The endogenous $\mathrm{CHO}$ stores are therefore likely to contribute to the higher rate of $\mathrm{CHO}_{\text {exo }}$ oxidation and may be related to pubertal status. On the other hand, young athletes were able to exercise at least $120 \mathrm{~min}$ at an intensity of $\sim 60 \%$ $\dot{\mathcal{V}} \mathrm{O}_{2 \max }$ without hypoglycaemia occurring (Boisseau \& Delamarche, 2000). These findings highlight the possibility of CHO-E supplementation to improve performance and contribute significantly to energy supply during prolonged intermittent exercise in young football players. Few studies have examined the effect of CHO-E supplementation in youth football using a modified football simulation protocol (SSP). Phillips et al. (2010) investigated the effects of $6 \%$ CHO-E supplementation on endurance capacity and sprint performance in 12-year-old boys during a $60 \mathrm{~min}$ intermittent soccer simulation exercise protocol. The results showed a significant improvement in endurance running capacity compared to the placebo trial. Time to fatigue was increased by $24.4 \%$ and total distance covered was greater in the $\mathrm{CHO}$ trial. A subsequent study by Phillips et al. (2012) also showed similar improvements on endurance capacity in 13-year-old team game players that ingested $0.818 \mathrm{~mL} \cdot \mathrm{kg}^{-1}$ $\mathrm{BM}$ of a CHO-E gel followed by $5 \mathrm{~mL} \cdot \mathrm{kg}^{-1} \mathrm{BM}$ of water $5 \mathrm{~min}$ before commencing the exercise. Participants consumed $0.327 \mathrm{~mL} \cdot \mathrm{kg}^{-1} \mathrm{BM}$ followed by $2 \mathrm{~mL} \cdot \mathrm{kg}^{-1} \mathrm{BM}$ of water during exercise. In both studies, there were no significant differences in HR, RPE and sprint times. However, these studies did not examine the effects of CHO-E ingestion on skill performance or metabolism due to ethical issues. These two measurements will provide more detailed information on the effects of CHO-E ingestion. These additional measures will show the effect of $\mathrm{CHO}-\mathrm{E}$ on various aspects of football-related performance; i.e. similar to what has been shown in adults.

Furthermore, Phillips et al. (2010 \& 2012) carried out their investigations in temperate conditions where they may sweat even less $\left(18-20^{\circ} \mathrm{C}\right.$ and $40-52 \%$ relative humidity). It can be deduced that $\mathrm{CHO}-\mathrm{E}$ ingestion will be more effective in a hot and humid environment. According to Mohr, Krustrup, and Bangsbo (2005), a hot and humid environment may decrease body fluid and lead to the development of fatigue towards the end of the game. This 
warrants further research investigating the effects of CHO-E ingestion in different climates. Nevertheless, it is also important to highlight that both studies were using a protocol (modified Loughborough Intermittent Shuttle Test; LIST, 60 min, running distance from 7.1 to $7.2 \mathrm{~km}$ ) which was initially designed for adult players who covered $8-12 \mathrm{~km}$ during a football match. Data from match analysis studies of children's football suggest that children do not perform an abbreviated version of the running demands of adults (Atan, Foskett \& Ali, 2014) and thus shortening the LIST may not be appropriate.

Indeed, the consumption of sugar-sweetened beverages in young football players is a hotly debated topic (Larson et al., 2014). Possible adverse effects of CHO-E ingestion include dental erosion associated with high citric acid content (Care, 2011) as well as excess calorie intake and weight gain (Larson et al., 2014). As the consumption of sports drinks increases, it is important to investigate the application of sports drinks in young athletes. Therefore, coaches and parents can educate their players/children about the appropriate consumption of sports drinks. Given the little evidence available, more research is warranted in CHO-E ingestion by using appropriate valid and reliable protocols for football players of various ages.

\section{CONCLUSION}

During prolonged intermittent exercise, football players always seek competitive advantages to win against their opponents. Since sports drinks or CHO-E beverages are readily available, the inclusion of sports drinks is common in young athletes. This is particularly because it is believed the potential sports performance benefits in adults such as improving sprint, football skills performances, endurance capacity and immune response to exercise may apply to young athletes as well. However, there is currently no evidence that these drinks improve football performance in youth players due to the following reason; youth football is possibly not of sufficient duration for these drinks to be effective ( $<90$ min playing time). In addition, there are concerns about added sugars in sports drinks which may have adverse side effects in children/adolescents such as an increased risk for poor dental health and excess energy intake that may lead to overweight/obesity. Furthermore, young people have a less well-developed thermoregulatory system than adults. It can be concluded that young athletes may prioritise fluid replacement ahead of $\mathrm{CHO}$ replacement as water might be better for children than sports drinks.

Currently, there are limited studies that investigated the efficacy of nutritional interventions in this population, mainly due to limited tools/ methodologies available. It is suggested that the development of a reliable football simulation protocol for young football players may be useful to investigate young players in various interventions.

\section{ACKNOWLEDGEMENTS}

The authors received no funding for the preparation of this review. The authors declare that they have no conflicts of interest that are directly relevant to the content of this review.

\section{REFERENCES}

[1] Ali, A \& Williams, C 2007, 'The influence of carbohydrate-electrolyte ingestion on soccer skill performance', Medicine and Science in Sports and Exercise, vol. 39, no. 11, pp. 1969-1976.

[2] Ali, A, Williams, C, Nicholas, CW \& Foskett, A 2009, 'Carbohydrate ingestion and soccer skill performance during prolonged intermittent exercise', Journal of Sports Sciences, vol. 27, no. 14, pp. 1499-1508.
[3] Alvarado, MU 2005, 'Nutrition for young soccer players', International Journal of Soccer and Science, vol. 3, no. 1, pp 12-20.

[4] Atan, SA, Foskett, A, Ali, A 2014, 'Special Populations : Issues and Considerations in Youth Soccer Match Analysis', Journal of Strength and Conditioning, vol. 4, no. 3, pp. 103-114.

[5] Bangsbo, J \& Lindquist, F 1992, 'Comparison of 
various exercise tests with endurance performance during soccer in professional players', International Journal of Sports Medicine, vol. 13, no. 2, pp. 125-132.

[6] Bangsbo, J, Mohr, M \& Krustup, P 2006, 'Physical and metabolic demands of training and matchplay in the elite football player', Journal of Sports Sciences, vol. 24, no. 7, pp. 665-674.

[7] Boisseau, N \& Delamarche, P 200o, 'Metabolic and hormonal responses to exercise in children and adolescents', Sports Medicine, vol. 30, no. 6, pp. $405-422$.

[8] Bradley, PS Mascio, MD, Peart, D, Olsen, P \& Sheldon, B 2010, 'High-intensity activity profiles of elite soccer players at different performance levels', Journal of Strength and Conditioning Research, vol. 24, no. 9, pp. 2343-2351.

[9] Care, RP 2011, 'Sports drinks and energy drinks for children and adolescents: are they appropriate?', Pediatrics, vol. 127, no. 6, pp. 1182-1189.

[10] Carling, C, Le Gall, F, Reilly, T \& Williams, AM 2009, 'Do anthropometric and fitness characteristics vary according to birth date distribution in elite youth academy soccer players?', Scandinavian journal of Medicine \& Science in Sports, vol. 19, no. 1, pp. 3-9.

[11] Carling, C, Le Gall, F \& Malina, RM 2012, 'Body size, skeletal maturity, and functional characteristics of elite academy soccer players on entry between 1992 and 2003', Journal of Sports Sciences, vol. 30, no. 15, pp. 1683-1893.

[12] Casa, DJ et al. 2000, 'National athletic trainers' association position statement: fluid replacement for athletes', Journal of Athletic Training, vol. 35, no. 2, pp. 212-224.

[13] Chamari, $\mathrm{K}$ et al. 2005, 'Appropriate interpretation of aerobic capacity: allometric scaling in adult and young soccer players', British Journal of Sports Medicine, vol. 39, no. 2, pp. 97101.

[14] Coyle, EF 1995, 'Substrate utilization during exercise in active people', American Journal of Clinical Nutrition, vol. 61, pp. 968-979.
[15] Currell, K, Conway, S \& Jeukendrup, AE 2009, 'Carbohydrate ingestion improves performance of a new reliable test of soccer performance', International Journal of Sport Nutrition and Exercise Metabolism, vol. 19, no. 1, pp. 34-46.

[16] Eating, $\mathrm{H}$ et al. 2012, Consumption of Sports Drinks by Children and Adolescents, viewed 5 January 2015, <http://www.healthyeatingresearch.org/images/st ories/her_research_briefs/RRSportsDrinkFINAL6 -2012.pdf. $>$

[17] Eriksson, BO, Gollnick, PD \& Saltin, B 1973, 'Muscle metabolism and enzyme activities after training in boys 11-13 years old', Acta Physiol Scand, vol. 87, pp. 485-497.

[18] Falk, B \& Dotan, R 2008, 'Children's thermoregulation during exercise in the heat: a revisit', Applied Physiology, Nutrition, and Metabolism, vol. 33, no. 2, pp. 420-427.

[19] Figueiredo, AJ et al. 2009, 'Characteristics of youth soccer players who drop out, persist or move up', Journal of Sports Sciences, vol. 27, no. 9, pp. 883891.

[20] Gant, N, Ali, A \& Foskett, A 2010, 'The influence of caffeine and carbohydrate coingestion on simulated soccer performance', International Journal of Sport Nutrition and Exercise Metabolism, vol. 20, no. 3, pp. 191-197.

[21] Gil, S, Ruiz, F, Irazusta, A, Gil, J \& Irazusta, J 2007, 'Selection of young soccer players in terms of anthropometric and physiological factors', Journal of Sports Medicine and Physical Fitness, vol. 47, no. 1 , pp. 25-32.

[22] Harris, JL et al. 2011, Sugary drink FACTS: Evaluating sugary drink nutrition and marketing to youth, viewed 5 January 2015, <http://www.sugarydrinkfacts.org/resources/suga rydrinkfacts_report.pdf>

[23] Helsen, WF, Van Wickel, J \& Williams, AM 2005, 'The relative age effect in youth soccer across Europe', Journal of Sports Sciences, vol. 23, no. 6, pp. 629-636.

[24] Hooper, S et al. 2004, 'A comparison of enamel 
erosion by a new sports drink compared to two proprietary products: A controlled, crossover study in situ', Journal of Dentistry, vol. 32, no. 7, pp. $541-545$

[25] Impellizzeri, EM, Rampinini, E \& Marcosa, SM 2005, 'Physiological assessment of aerobic training in soccer', Journal of Sports Sciences, vol. 23, no. 6, pp. 583-592.

[26] Kostyak, JC et al. 2007, 'Relative fat oxidation is higher in children than adults', Nutrition Journal, vol. 6, pp 6-19.

[27] Krustrup, P et al. 2003, 'The yo-yo intermittent recovery test: physiological response, reliability, and validity', Medicine and Science in Sports and Exercise Science, vol. 35, no. 4, pp. 697-705.

[28] Krustrup, P et al. 2006, 'Muscle and blood metabolites during a soccer game: Implications for sprint performance', Medicine and Science in Sports and Exercise, vol. 38, no. 6, pp. 1165-1174.

[29] Kunz, M 2007, 265 million playing football, $\begin{array}{llll}\text { viewed } & 21 & \text { November } & 2014\end{array}$ <https://www.fifa.com/mm/document/fifafacts/b coffsurv/emaga_9384_10704.pdf>

[30] Larson, N, Dewolfe, J, Story, M \& NeumarkSztainer, D 2014, 'Adolescent consumption of sports and energy drinks: linkages to higher physical activity, unhealthy beverage patterns, cigarette smoking, and screen media use', Journal of Nutrition Education and Behavior, vol. 46, no. 3, pp. 181-187.

[31] Le Gall, F, Carling, C, Williams, M \& Reilly, T 2010, 'Anthropometric and fitness characteristics of international, professional and amateur male graduate soccer players from an elite youth academy', Journal of Science and Medicine in Sport, vol. 13, no. 1, pp. 90-95.

[32] Malina, RM, Eisenmann, JC, Cumming, SP, Ribeiro, B \& Aroso, J 2004, 'Maturity-associated variation in the growth and functional capacities of youth football soccer players 13-15 years', Journal of Sports Sciences, vol. 23, no. 5, pp. 515-522.

[33] Malina, RM et al. 2011, 'Height, mass and skeletal maturity of elite Portuguese soccer players aged 11
- 16 years', Journal of Sports Sciences, vol. 18, no. 9, pp. 685-693.

[34] Marshall, WA \& Tanner, JM 1970, 'Variations in the pattern of pubertal changes in boys', Archives of Disease in Childhood, vol. 45, no. 239, pp. 13-23.

[35] Maughan, RJ 1998, 'The sports drink as a functional food: formulations for successful performance', The Proceedings of the Nutrition Society, vol. 57, pp. 15-23.

[36] Maughan, RJ, King, D \& Lea, T 2004, 'Dietary Supplements', Journal of Sports Sciences, vol. 22, no. 1 , pp. 95-113.

[37] Mcgregor, SJ, Nicholas, CW, Lakomy, HK \& Williams, C 1999, 'The influence of intermittent high-intensity shuttle running and fluid ingestion on the performance of a soccer skill', Journal of Sports Sciences, vol.17, no.11, pp. 895-903.

[38] Meylan, C, Cronin Joliver, J \& Hughes, M 2010, 'Reviews: Talent Identification in Soccer: The Role of Maturity Status on Physical, Physiological and Technical Characteristics', International Journal of Sports Science and Coaching, vol. 5, no. 4, pp. 571592.

[39] Mohr, M, Krustrup, P \& Bangsbo, J 2003, 'Match performance of high-standard soccer players with special reference to development of fatigue', Journal of Sports Sciences, vol. 21, no. 7, pp. 519528.

[40] Mohr, M, Krustrup, P \& Bangsbo, J 2005, 'Fatigue in soccer: a brief review', Journal of Sports Sciences, vol. 23, pp. 593-599.

[41] Monteiro, CR, Guerra, I \& Barros, TL 2003, 'Hydration in soccer : a review', Revista Brasileira de Medicine do Esporte, vol. 9, pp. 243-246.

[42] Montfort-Steiger, V \& Williams, CA 2007 , 'Carbohydrate intake considerations for young athlete', Journal of Sports Science and Medicine, 6 , pp. $343-352$.

[43] Naughton, G et al. 2000, 'Physiological issues surrounding the performance of adolescent athletes', Sports Medicine, vol. 30, no. 5, pp. 309325

[44] Nicholas, CW, Williams, C, Lakomy, HK Phillips, G 
\& Nowitz, A 1995, 'Influence of ingesting a carbohydrate-electrolyte solution on endurance capacity during intermittent, high-intensity shuttle running, Journal of Sports Sciences, vol. 13, no. 4, pp. 283-290.

[45] Nicholas, CW, Tsintzas, K, Boobis, L \& Williams, C 1999, 'Carbohydrate-electrolyte ingestion during intermittent high-intensity running', Medicine and Science in Sports and Exercise, vol. 31, no. 9, pp. 1280-1286.

[46] Nikolaidis, PT 2011, 'Anaerobic power across adolescence in soccer players', Human Movement, vol. 12, no. 4, pp. 342-347.

[47] Osgnach, C, Poser, S, Bernardini, R, Rinaldo, R \& Di Prampero, PE 2010, 'Energy cost and metabolic power in elite soccer: a new match analysis approach', Journal of Sports Science and Medicine, vol. 42, no. 1, pp. 170-178.

[48] Patterson, SD \& Gray, SC 2007, 'Carbohydrate-gel supplementation and endurance performance during intermittent high-intensity shuttle running', International Journal of Sport Nutrition and Exercise Metabolism, vol. 7, no. 5, pp. 445-455.

[49] Philippaerts, RM et al. 2006, 'The relationship between peak height velocity and physical performance in youth soccer players', Journal of sports sciences, vol. 24, no. 3, pp. 221-30.

[50] Phillips, SM et al. 2010, 'Ingesting a 6\% carbohydrate-electrolyte solution improves endurance capacity, but not sprint performance, during intermittent, high-intensity shuttle running in adolescent team games players aged 12-14 years', European Journal of Applied Physiology, vol. 109, no. 5, pp. 811-821.

[51] Phillips, SM et al. 2012, 'Carbohydrate gel ingestion significantly improves the intermittent endurance capacity, but not sprint performance, of adolescent team games players during a simulated team games protocol', European Journal of Applied Physiology, vol.112, no. 3, pp. 1133-1141.

[52] Powers, SK \& Howley, ET 2001, Exercise Physiology: Theory and Application to Fitness and Performance, Ed Human Kinetics Pub
Champign, London, McGraw-Hill.

[53] Rampinini, E et al. 2009, 'Technical performance during soccer matches of the Italian Serie A league: effect of fatigue and competitive level', Journal of Science and Medicine in Sport, vol. 12, no. 1, pp. 227-233.

[54] Reilly, T, Bangsbo, J \& Franks, A 2000, 'Anthropometric and physiological predispositions for elite soccer', Journal of Sports Sciences, vol. 18, no. 9, pp. 669-683.

[55] Reilly, T \& Thomas, V 1976, 'A motion analysis of work rate in different positional roles in professional football match play', Journal Human Movement Studies, vol. 2, pp. 87-97.

[56] Riddell, MC 2008, 'The endocrine response and substrate utilization during exercise in children and adolescents', Journal of Applied Physiology, vol. 105, no. 2, pp. 725-733.

[57] Rosenbloom, CA, Loucks, AB \& Ekblom, B 2006, 'Special populations: the female player and the youth player', Journal of Sports Sciences, vol. 24, no. 7 , pp. $783-793$.

[58] Rowland, $\mathrm{T}$ 2008, 'Thermoregulation during exercise in the heat in children: old concepts revisited', Journal of Applied Physiology, vol.105, no. 2, pp. 718-724.

[59] Ruiz, F et al. 2005, 'Nutritional intake in soccer players of different ages', Journal of Sports Sciences, vol. 23, no. 3, pp. 235-242.

[6o] Russell, M, Benton, D \& Kingsley, M 2011, 'The effects of fatigue on soccer skills performed during a soccer match simulation', International Journal of Sports Physiology and Performance, vol. 6, no. 2, pp. 221-233.

[61] Russell, M \& Kingsley, M 2014, 'The efficacy of acute nutritional interventions on soccer skill performance', Sports Medicine, vol. 44, no.7, pp. 957-970.

[62] Sawka, MN \& Montain, SJ 2000, 'Fluid and electrolyte supplementation for exercise heat stress', The American Journal of Clinical Nutrition, vol. 72, no. 2 Suppl, pp. 564S-572S.

[63] Shi, X \& Gisolfi, CV 1998, 'Fluid and carbohydrate 
replacement during intermittent exercise', Sports Medicine, vol. 25, no. 3, pp. 157-172.

[64] Silva, RP et al. 2011, 'Fluid balance of elite Brazilian youth soccer players during consecutive days of training', Journal of Sports Sciences, vol. 29, no. 7, pp. 725-732.

[65] Sinclair, WH et al. 2007, 'Pre-pubertal children and exercise in hot and humid environments: A brief review', Journal of Sports Science and Medicine, vol. 6, pp. 385-392.

[66] Smith, J 1992, 'A look at the components and effectiveness of sports drinks', Journal of Athletic Training, vol. 27, no. 2, pp. 173-176.

[67] Stølen, T, Chamari, K, Castagna, C \& Wisløff, U 2005, 'Physiology of Soccer', Sports Medicine, vol. 35 , no 6 , pp. 501-536.

[68] Strøyer, J, Hansen, L \& Klausen, K 2004, 'Physiological profile and activity pattern of young soccer players during match play', Medicine and Science in Sports and Exercise Science, vol. 36, no. 1, pp. 168-174

[69] Svensson, M \& Drust B 2005, 'Testing soccer players', Journal of Sports Sciences, vol. 23, no. 6, pp. 601-618.

[70] Teplan, J. et al. 2012, "The level and differences of aerobic capacity in three different young soccer teams in the U17 category', Sport Science, vol. 5, no. 2012 1, pp. $43-48$

[71] Thein, LA, Thein, JM \& Landry, GL 1995, 'Ergogenic aids', Physical Therapy, vol. 75, no. 5, pp. 426-439.

[72] Timmons, BW, Bar-Or, O \& Riddell, MC 2003, 'Oxidation rate of exogenous carbohydrate during exercise is higher in boys than in men', Journal of Applied Physiology (Bethesda, Md. : 1985), vol. 94, no. 1, pp. 278-284.

[73] Timmons, BW, Bar-Or, O \& Riddell, MC 2007a, 'Energy substrate utilization during prolonged exercise with and without carbohydrate intake in preadolescent and adolescent girls', Journal of applied physiology (Bethesda, Md.: 1985), vol. 103, no. 3, pp. 995-1000.

[74] Timmons, BW, Bar-Or, O \& Riddell, MC 2007b,
'Influence of age and pubertal status on substrate utilization during exercise with and without carbohydrate intake in healthy boys', Journal of Applied Physiology, vol. 32, no. 3, pp. 416-425.

[75] Vigne, G et al. 2010, 'Activity profile in elite Italian soccer team', International Journal of Sports Medicine, vol. 31, no.5, pp. 304-310.

[76] Yoav, M, Machnai, O \& Eliakim, A 2009, 'Relationship among repeated sprint tests, aerobic fitness, and anaerobic fitness in elite adolescent soccer players', Journal of Strength and Conditioning Research, vol. 23, no. 1, pp. 163-169. 